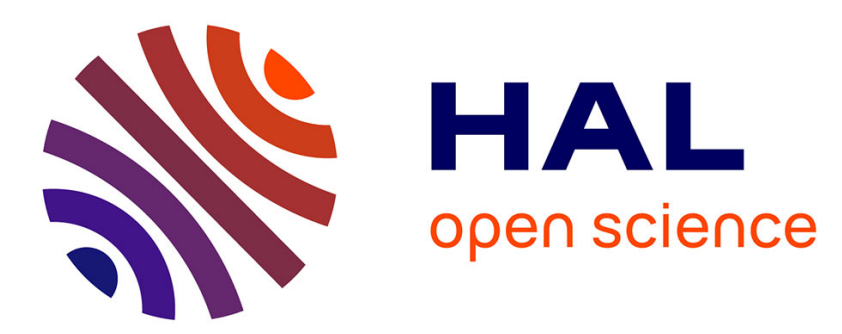

\title{
Mössbauer effect evidence for disordering induced by mechanical alloying in the Fe-Si system
}

\author{
M. Abdellaoui, E. Gaffet, C. Djega-Mariadassou, T. Barradi
}

\section{To cite this version:}

M. Abdellaoui, E. Gaffet, C. Djega-Mariadassou, T. Barradi. Mössbauer effect evidence for disordering induced by mechanical alloying in the Fe-Si system. Journal de Physique IV Proceedings, 1994, 04 (C3), pp.C3-285-C3-290. 10.1051/jp4:1994339 . jpa-00252536

\section{HAL Id: jpa-00252536 https://hal.science/jpa-00252536}

Submitted on 1 Jan 1994

HAL is a multi-disciplinary open access archive for the deposit and dissemination of scientific research documents, whether they are published or not. The documents may come from teaching and research institutions in France or abroad, or from public or private research centers.
L'archive ouverte pluridisciplinaire HAL, est destinée au dépôt et à la diffusion de documents scientifiques de niveau recherche, publiés ou non, émanant des établissements d'enseignement et de recherche français ou étrangers, des laboratoires publics ou privés. 


\title{
Mössbauer effect evidence for disordering induced by mechanical alloying in the Fe-Si system
}

\author{
M. ABDELLAOUI, E. GAFFET, C. DJEGA-MARIADASSOU* and T. BARRADI**
}

ISITEM-CNRS, Groupe "Elaboration et Transitions de Phase loin de l'Equilibre" La Chantrerie, Rue C. Pauc, CP. 3023, 44087 Nantes cedex 03, France

* Laboratoire de Structure des Matériaux Métalliques, Bât. 413-414, Université Paris-Sud, 91405 Orsay cedex, France

** Supelec, 91192 Gif-sur-Yvette cedex, France

\section{ABSTRACT :}

Based on $\mathrm{X}$ - ray diffraction (XRD) patterns, differential scanning calorimetry (DSC) investigations, the phase transitions induced by mechanical alloying (MA) on the Fe rich side of the Fe - Si system has been studied. Starting from a mixture of Fe and Si powders, MA leads to an expansion (up to 27.5 at. \% Si) of the A2 crystalline disordered solid solution phase domain. In this composition field, an amorphous phase is also detected.

The expansion of the disordered A2 phase domain up to 27.5 at. $\%$ Si has been confirmed by Mössbauer spectroscopy investigations. An annealing of the mechanically alloyed powders at $800^{\circ} \mathrm{C}$ for 48 hours leads exactly to the thermodynamically stable structures consistent with the sample stoechiometry. A high coercive force value of $17.2 \mathrm{kA} / \mathrm{m}$ at $1 \mathrm{kHz}$ frequency and $0.15 \mathrm{~T}$ magnetic induction was reported for the 9.5 at. $\% \mathrm{Si}$.

\section{INTRODUCTION:}

The relationship between the crystal structure and the magnetic properties in Fe Si bulk alloys has been extensively studied so far [1 - 3]. The phase diagram has been already reported $[4,5]$ and three kinds of crystal structures are known in the $\mathrm{Fe}-\mathrm{Si}$ system : A2 disordered, B2 ordered, and DO3 ordered structures.

Based on Mössbauer spectroscopy, M. B. Stearns [6] has examined the structures and the magnetism of $\mathrm{Fe}$ - $\mathrm{Si}$ alloys, in the thermodynamically stable state and has reported the values of the internal magnetic fields, the isomer shifts and the abundances of $57 \mathrm{Fe}$ atoms residing at various sites. In the thermodynamically stable state, for $\mathrm{Si}$ content less than 10 at.\% Si, the alloys go into the A2-type disordered structure and three different type sites were observed [6]. These correspond to $\mathrm{Fe}$ atoms having 8,7 and 6 nearest-neighbor Fe atoms. For this $\mathrm{Si}$ content range, the internal field decreased by 0.08 $\mathrm{HFe}_{\mathrm{Fe}}\left(\mathrm{H}_{\mathrm{Fe}}=330 \mathrm{kOe}\right.$ ) for each $\mathrm{Si}$ nearest-neighbor. For Si content larger than 10 at.\% Si, the author [6] shows that the alloys try to go into Fe3Al (DO3) type structure. Sites having 8 (D-type site) through 3 ( $\mathrm{A}_{3}$-type site) nearest-neighbor Fe atoms were observed. For Atype site, ( 4 nearest-neighbor Fe atoms and 4 nearest-neighbor $\mathrm{Si}$ atoms at 25 at.\% $\mathrm{Si}$ ), the internal field decreased by $0.14 \mathrm{HFe}$ for each $\mathrm{Si}$ nearest-neighbor.

Amorphous thin film of $1 \mu \mathrm{m}$ has been prepared by deposition on crystallized glass substrates by planar magnetron sputtering [7]. The amorphous structure in the assputtered $\mathrm{Fe}+28.4$ at.\% Si thin film transformed into DO3-type ordered structure due to the annealing at $500^{\circ} \mathrm{C}$ was examined by conversion electron Mössbauer spectroscopy. The authors [7] reported on the existence of three kinds of Fe sites having the internal 
magnetic fields of 314,203 and $129 \mathrm{kOe}$. These correspond to Fe atoms having respectively 8 nearest-neighbor $\mathrm{Fe}$ atoms (D site), $4 \mathrm{Fe}+4 \mathrm{Si}$ nearest-neighbor $\left(\mathrm{A}_{4}\right.$ site) and finally 3 $\mathrm{Fe}+5 \mathrm{Si}$ nearest-neighbor ( $\mathrm{A}_{3}$ site $)$.

Starting from a mixture of Fe and $\mathrm{Si}$ powders, we report in our previous works [8 10], on the expansion, up to 27.5 at.\% $\mathrm{Si}$, of the $\mathrm{A} 2$ crystalline solid solution phase domain. In the present paper, direct evidence is given for the structural disordering resulting from MA by a comparison between the hyperfine parameters of some presented MA samples and those corresponding to the same samples subsequently annealed. Three typical samples were chosen with $\mathrm{Si}$ content sufficiently high to correlate the disordered state : 15.0, 18.1 and 27.5 at.\% Si. Results concerning other contents will be reported later.

\section{EXPERIMENTAL PROCEDURE :}

Starting from a mixture of $\mathrm{Fe}$ and $\mathrm{Si}$ powders, the MA was carried out using a classical P5/2 (10) Fritsch planetary high-energy ball mill. For more details, see ref. [8, 9].

The Mössbauer spectra were collected at room temperature from a 512 channel spectrometer operating in the mirror image mode in transmission geometry with a $50 \mathrm{mC} \mathrm{Co57/Rh} \mathrm{source.} \mathrm{The} \mathrm{spectra} \mathrm{were} \mathrm{computer} \mathrm{fitted} \mathrm{assuming} \mathrm{lorentzian} \mathrm{lines} \mathrm{with}$ two distinct methods. The first one required several discrete broadened sextets [11]. The hyperfine parameters deduced were then used in the second procedure derived from the Hess-Rubartsch method [12] to obtain the hyperfine field distribution $P(H)$ with correlation between isomer shift $\delta$ and quadrupolar splitting $\varepsilon$. The line width $\Gamma$ was taken equal to : $0.24 \mathrm{~mm} \mathrm{~s}^{-1}$.

\section{RESULTS AND DISCUSSIONS :}

\section{1) Fnd product structural state :}

Structural state investigations is carried on by XRD pattern carried out using a ( $\theta$ 20) Philips diffractometer with the $C_{0} K_{\alpha}$ radiation $(\lambda=0.17889 \mathrm{~nm})$.

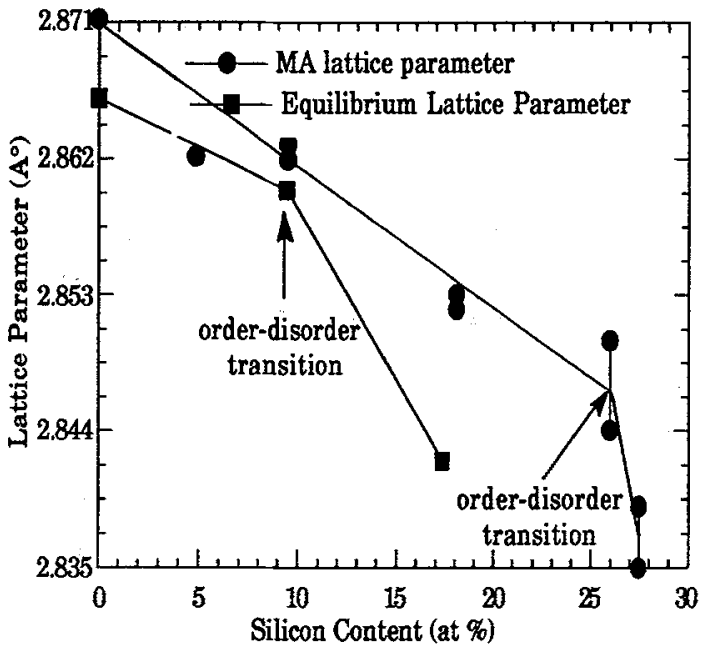

Fig. 1 : Lattice parameter as a function of Si content. (from [8 - 10])

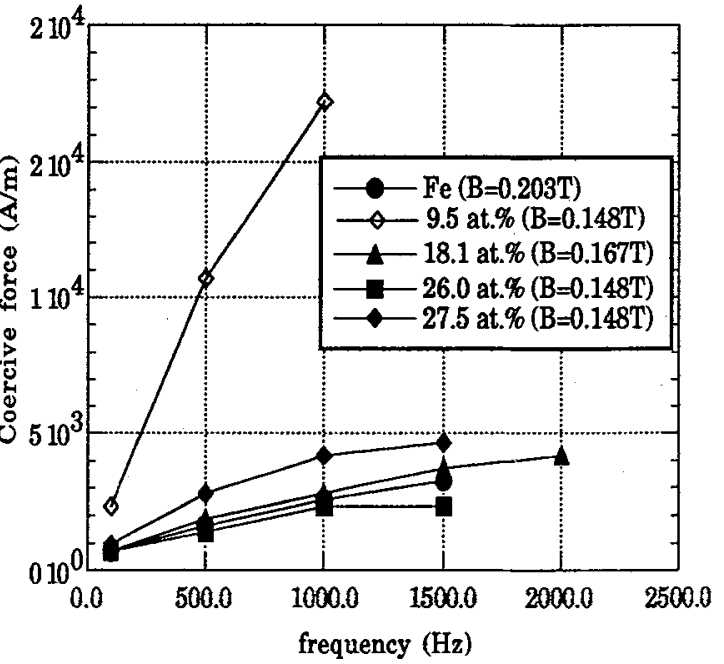

Fig. 2 : Coercivity as a function of frequency. (from [8])

Based on these XRD pattern investigations, in the 0 up 27.5 at.\% Si composition range, the A2 c.c disordered solid solution phase and an amorphous phase at the same 
content in silicon were detected. According to the Fe - Si phase diagram, the A2 phase domain has been considerably enlarged (the equilibrium value is $\sim 9$ at.\% [3]).

Fig. 1 shows the lattice parameter of both, the ball milled and stable states, as a function of the Si content. Fig. 2 exhibits the ball milled coercive force as a function of the frequency. The ball milled crystalline grain sizes are very small $(5 \sim 10 \mathrm{~nm})$ leading to high coercive forces $(17.2 \mathrm{k} \mathrm{A} / \mathrm{m}$ at $1 \mathrm{kHz}$ frequency and $0.15 \mathrm{~T}$ magnetic induction was reported for the 9.5 at. \% $\mathrm{Si}$ ). For more details on the magnetic properties, see ref. [8].

\section{2) Mössbauer investigations in the ball milled and annealed states :}

The Mössbauer spectra of the ball milled samples differ drastically from those resulting from the subsequent annealing (Fig. $3 \mathrm{a}$ and $3 \mathrm{~b}$ ).

\section{a) ball milled state :}

The spectra Fig. 3a are characterized by broadened lines. the discrete site procedure needed at least 9 enlarged sextets to obtain a good quality of fits $(\Gamma$ sextets $=0.30 \mathrm{~mm} \mathrm{~s}-1)$. The deduced hyperfine field distribution $\mathrm{P}(\mathrm{H})$ (Fig. 4a) attests for a continuous iron population consistent with the existence of numerous neighboring increasing with Si content.

The higher Si content, the lower the internal field $H$ and the higher the isomer shift $\delta$. $\langle\mathrm{H}\rangle$ is equal to $28.9,27.0$ and $19.7 \mathrm{~T}$, and $<\delta>$ is equal to $0.079,0.101$ and 0.131 $\mathrm{mm} \mathrm{s}^{-1}$ respectively for $15.0,18.1$ and 27.5 at.\% Si samples.

As lorentzian lines with the correct ratios 3:2:1 gave, in all field ranges a good reproduction of the spectra, whatever the $\mathrm{Si}$ content values, it can be deduced that atomic disorder is responsible for the spectra enlargement rather than relaxation phenomena which could occur for such particle sizes.

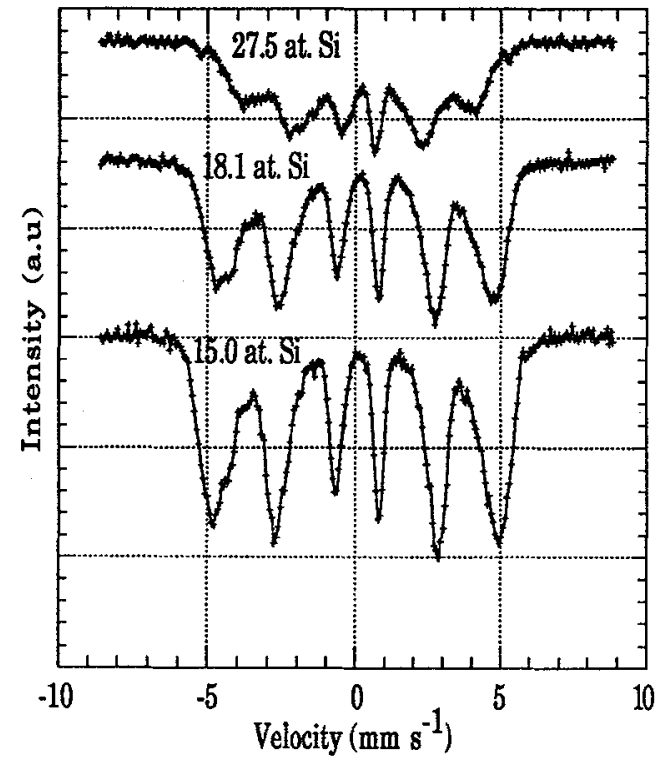

(a)

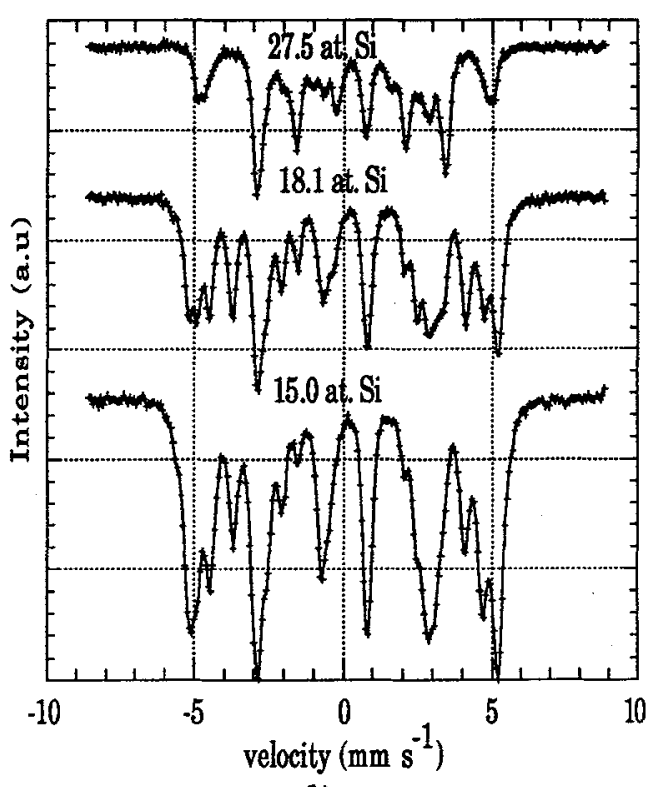

(b)

Fig. 3 : Mössbauer spectra corresponding to a): the ball milled state $b)$ : the annealed state 


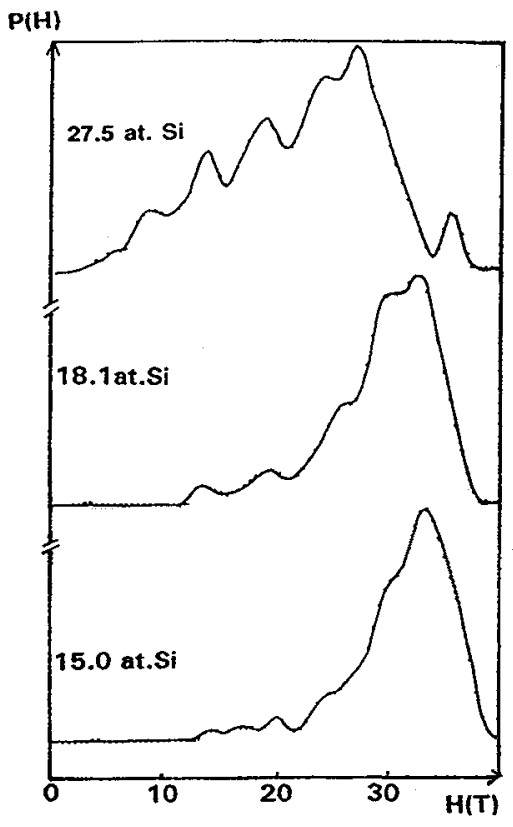

(a)
$\mathbf{P ( H )}$

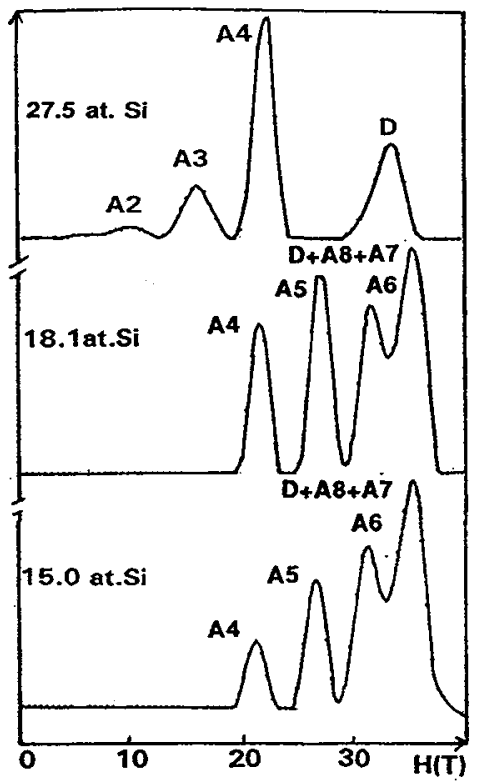

(b)

Fig. 4 : Hyperfine field distributions corresponding to a) : ball milled state and b) : annealed state.

Table 1: Measured values of the internal magnetic fields, the isomer shifts and the relative intensities of the different sites in the ball milled alloys. The accuracy for $H, \delta$ and the relative intensity are respectively $\pm 0.1 T, \pm 0.010 \mathrm{~mm} / \mathrm{s}$ and $\pm 2 \%$.

\begin{tabular}{|l|l|l|l|l|l|l|l|}
\hline at.\% Si & H (T) & $\begin{array}{c}\text { IS } \\
(\mathrm{mm} / \mathrm{s})\end{array}$ & $\begin{array}{c}\text { relative } \\
\text { intensity }\end{array}$ & at.\% Si & H (T) & $\begin{array}{c}\text { IS } \\
(\mathrm{mm} / \mathrm{s})\end{array}$ & $\begin{array}{c}\text { relative } \\
\text { intensity }\end{array}$ \\
\hline 15.0 & 33.3 & 0.045 & 9.8 & & 23.6 & 0.164 & 7.2 \\
\hline & 32.0 & 0.056 & 14.1 & & 22.2 & 0.194 & 5.7 \\
\hline & 30.7 & 0.060 & 18.1 & & 20.4 & 0.189 & 4.4 \\
\hline & 29.6 & 0.070 & 11.0 & & 16.9 & 0.174 & 5.6 \\
\hline & 28.9 & 0.077 & 9.4 & 27.5 & 32.7 & 0.064 & 3.3 \\
\hline & 27.6 & 0.083 & 13.6 & & 28.9 & 0.068 & 4.6 \\
\hline & 26.2 & 0.099 & 10.4 & & 25.0 & 0.085 & 10.9 \\
\hline & 24.1 & 0.140 & 7.8 & & 25.2 & -0.116 & 4.1 \\
\hline & 21.5 & 0.150 & 5.7 & & 23.5 & 0.194 & 7.5 \\
\hline 18.1 & 33.0 & 0.054 & 5.4 & & 22.1 & 0.114 & 9.5 \\
\hline & 31.6 & 0.059 & 9.2 & & 20.6 & 0.135 & 8.2 \\
\hline & 30.5 & 0.111 & 11.2 & & 18.8 & 0.189 & 5.9 \\
\hline & 29.5 & 0.030 & 11.8 & & 17.0 & 0.195 & 8.2 \\
\hline & 28.4 & 0.071 & 10.8 & & 14.6 & 0.197 & 9.8 \\
\hline & 27.6 & 0.053 & 7.7 & & 12.3 & 0.156 & 8.3 \\
\hline & 26.6 & 0.098 & 12.7 & & 9.9 & 0.264 & 5.4 \\
\hline & 25.2 & 0.145 & 8.2 & & 4.1 & 0.202 & 5.6 \\
\hline
\end{tabular}

In the case of 27.5 at.\% $\mathrm{Si}$ sample, it is worthwhile to note that a noticeable fraction of the iron population $\sim 20 \%$ shows weak hyperfine fields $\sim 10 \mathrm{~T}$. Theses fields concern local environment enriched in Si. In the other hand, it was reported by R. Z. Valiev et al. [13] that the iron atoms occupying the grain boundaries have a high internal magnetic field ( $300 \mathrm{kOe})$ with a population fraction of about $9 \%$ at $300 \mathrm{~K}$. Thus, we assume that the 
related fraction $(\sim 20 \%)$ of iron population, with low values, is not due to iron in grain boundaries.

\section{b) annealed state :}

The spectra are typical of those obtained in the ordered region in the $\mathrm{Fe}$ - $\mathrm{Si}$ system [6]. The experimental populations distribution is in perfect agreement with the theoretical population calculated from each Si content in the model of the DO3 structure (Table 2) (Fig. 4b). $\bar{H}$ is equal to $28.6 \mathrm{~T}, 27.3 \mathrm{~T}$ and $22.0 \mathrm{~T}$ with $\bar{\delta}$ equal to $0.087 \mathrm{~mm} / \mathrm{s}$, $0.123 \mathrm{~mm} / \mathrm{s}$ and $0.212 \mathrm{~mm} / \mathrm{s}$ for the three samples.

Between 14 to 25 at.\% $\mathrm{Si}[6]$ the $\mathrm{Si}$ atoms have an equal probability to occupy any of the D-type $\mathrm{Si}$ sites shown in Fig. 5. Above 25 at.\% $\mathrm{Si}$, we assume that the $\mathrm{Si}$ atoms go randomly into the $\mathrm{D}$-type -Fe sites. The notation used in the text to differentiate the various $A$ sites is $A_{n}$, where $n$ is the number of nearest-neighbor (nn) Fe atoms. Based on Fig. 5 , it is easy to see that all $D$ sites have eight $n n$ iron atoms and all A-type sites have six next-nearest-neighbor ( $\mathrm{nnn}$ ) Fe atoms for all compositions.

Table 2: Measured values of the internal magnetic fields, the isomer shifts and the relative intensities of the different sites in the annealed alloys. The respective accuracy for $H, \delta$ and the relative intensity is generally of $\pm 0.1 T, \pm 0.010 \mathrm{~mm} / \mathrm{s}$ and $\pm 2 \%$.

\begin{tabular}{|l|l|l|l|l|l|}
\hline $\begin{array}{c}\text { Si Content } \\
\text { (\% at.) }\end{array}$ & $\begin{array}{l}\text { internal } \\
\text { field (T) }\end{array}$ & $\begin{array}{c}\text { isomer shift } \\
\text { mm s }\end{array}$ & $\begin{array}{c}\text { measured relative } \\
\text { intensity (\%) }\end{array}$ & $\begin{array}{c}\text { calculated relative } \\
\text { intensity (\%) }\end{array}$ & 57 Fe Site type \\
\hline 15.0 & 31.8 & 0.0362 & 51.2 & $41.17+1.51+9.04$ & $\mathrm{D}+\mathrm{A} 8+\mathrm{A} 7$ \\
\hline & 28.4 & 0.089 & 20.1 & 20.33 & $\mathrm{~A} 6$ \\
\hline & 24.6 & 0.143 & 20.6 & 20.33 & $\mathrm{~A} 5$ \\
\hline & 19.1 & 0.262 & 8.1 & 7.62 & $\mathrm{~A} 4$ \\
\hline 18.0 & 31.8 & 0.055 & 39.6 & $38.95+0.35+3.72$ & $\mathrm{D}+\mathrm{AB}+\mathrm{A} 7$ \\
\hline & 28.7 & 0.096 & 16.6 & 14.63 & $\mathrm{~A} 6$ \\
\hline & 24.8 & 0.157 & 27.5 & 25.58 & $\mathrm{~A} 5$ \\
\hline & 19.3 & 0.259 & 16.3 & 16.77 & $\mathrm{~A} 4$ \\
\hline 27.5 & 30.1 & 0.083 & 30.8 & 31.03 & $\mathrm{D}$ \\
\hline & 19.7 & 0.249 & 50.2 & 45.25 & $\mathrm{~A} 4$ \\
\hline & 14.6 & 0.286 & 19.0 & 20.11 & $\mathrm{A3}$ \\
\hline & 10.0 & 0.300 & 2.5 & 3.35 & $\mathrm{~A} 2$ \\
\hline
\end{tabular}

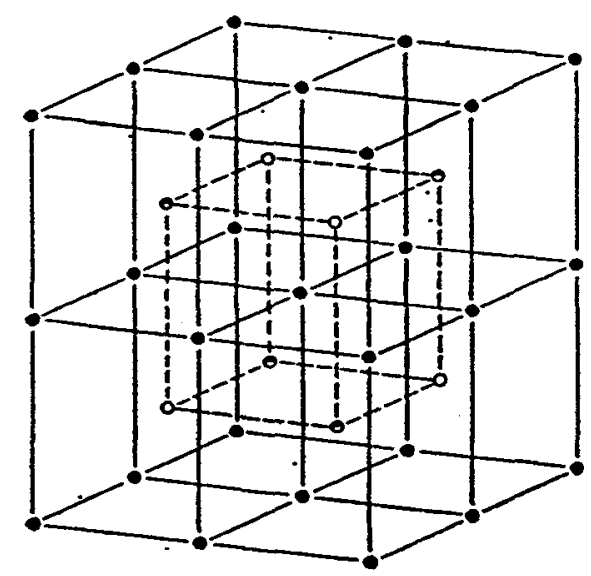

Fig. 5 : Unit cell of the ordered Fe3Si structure (from [6]).

- Fe otoms on A sites

- Fe atoms on D sites

- Si afoms on D aites 
15.0 and 18.1 at.\% Si. For 15.0 at. Si content alloy the Mössbauer spectra shows 4 easily resolved fields. The value of the highest field is $31.8 \mathrm{~T}$. Its relative intensity is $51.2 \%$. Based on the calculated values of probability of the various sites (Table 2), the highest field is expected to contain $79.6 \% \mathrm{D}$ site $\mathrm{Fe}$ atoms and $20.4 \% \mathrm{~A}_{8}+\mathrm{A}_{7}$ site $\mathrm{Fe}$ atoms. The intensities of the other 3 fields well agree with being assigned to $A_{6}{ }^{-}, A_{5}-$ and $A_{4}$-type sites. For the 18.1 at.\% $\mathrm{Si}$ content alloy, 4 different magnetic fields are observed. These are the same 4 fields as seen in the 15.0 at.\% $\mathrm{Si}$ alloy. The measured intensities agree reasonably well with the calculated values (Table 2). These 4 fields correspond to the 4 peaks in the hyperfine field distributions shown in Fig. 4 b.

27.5 at.\% Si: Four fields are detected. Based on Table 2, the measured intensities of these 4 fields agree with those of D-, A4- A3- and A2-type sites. These 4 fields correspond to the 4 peaks in the hyperfine field distribution given in Fig. $4 \mathrm{~b}$.

It must be emphasized that the mean hyperfine field value for the ball-milled and annealed samples are very close although the hyperfine field distribution $\mathrm{P}(\mathrm{H})$ profiles look different. The ball-milled samples are relevant of structural disorder for which many reasons can be invoked. Even in the case of a classical substitution, the numerous sites can result from the existence of numerous Fe first neighbor or Fe second neighbor distances varying around a mean value corresponding to that of the crystallized samples with similarities to a Hosemann paracrystalline disorder.

Unlike Elsukov et al. [14] who ball milled Fe-Si alloys, we have obtained directly from, Fe and Si powders, the disordered crystalline site showing that the extend of the reaction between iron and silicon is high and that without an external thermal contribution a solid solution occurred.

\section{CONCLUSIONS :}

For each $\mathrm{Si}$ content, the MA powder annealing at $800^{\circ} \mathrm{C}$ leads exactly to the thermodynamically stable structures corresponding to the nominal stoechiometry. This clearly proves the efficiency of the ball milling technique.

The Mössbauer spectra of the ball-milled samples are explained by a continuous $\mathrm{P}(\mathrm{H})$ distribution up to 27.5 at.\% Si, typically representative of structural disorder. Calculations are being carried on to check the existence of a binomial disorder of A2 type or that of higher disordered systems.

\section{References :}

[1] J. Degauque, D. Bouchara, M. Fagot, J. Baras, J. P. Redoules, Ph. Chomel and B. Astie, IEEE Transactions on Magnetics, Vol. 26, $N^{\circ} 5$, (1990) 2220 - 2222

[2] Kenji Narita and Masato Enokisono, IEEE Transactions on Magnetics, Vol. Mag. 15, $N^{\circ} 1$, (1979) 911-915

[3] M. J. Tenwick and H. A. Davies, Int. J. Rapid Sol., Vol. 1, (1984 - 85) 143 - 155

[4] P. R. Swann, C. Granas and B. Lehtinen, Metal Science, Vol. 9, (1975) 90 - 96

[5] Kubaschewski, "Fe - Si ; iron - silicon, iron binary phase diagram", Springer, Berlin, 1982, pp. 136 139

[6] M. B. Stearns, Phys. Rev., Vol. 129, N³, (1963) 1136 - 1144

[7] Masahiro Miyazaki, Masashi Ichikawa, Takayuki Komatsu and Kazumasa Matusita, J. Appl. Phys. 71(5), (1992) 2368 - 2374

[8] M. Abdellaoui, T. Barradi and E. Gaffet, J. of Alloys and Compounds (in press)

[9] M. Abdellaoui, T. Barradi and E. Gaffet, Journal de Physique IV, Colloque C3, Supplèment au Journal de physique III, Vol. 2, 1992

[10] E. Gaffet, N. Malhouroux and M. Abdellaoui, J. of Alloys and Compounds, 194 (2) (1993) 339 - 360

[11] J. L. Dormann, L. Brossard, G. A. Fatseas, Phys. Stat. Sol. B 52 (K23) (1972)

[12] G. Le Caër, J. M. Dubois J. Phys. E 12 (1979) 1083

[13] R. Z. Valiev, R. R. Mulyukov, V. V. Ovchinnikov and V. A. Shabaskov, Scripta. Metall. Mater. Vol. 25 (1991) 2717 - 2722

[14] E. P. Elsukov, G. N. Konygin, V. A. Barinov and E. V. Voronina, J. Phys. : Condens. Matter. 4 (1992) $7597-7606$ 